\title{
No Impact? Long-Term Effects of Applying the Best Possible Self Intervention in a Real-World Undergraduate Classroom Setting
}

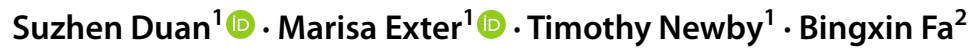

Received: 26 October 2020 / Accepted: 18 March 2021 / Published online: 21 April 2021

(c) The Author(s), under exclusive licence to Springer Nature Switzerland AG 2021

\begin{abstract}
Positive psychology interventions (PPIs) improve students' well-being in laboratory settings. Best possible self (BPS) is one of the most widely used PPIs shown in the laboratory to effectively improve participants' well-being in both the shortand long-term, but limited research has been conducted in real-world contexts. This study applied BPS in an undergraduate classroom to examine its long-term effects. Students enrolled in an undergraduate education course were assigned to treatment and control groups. Three writing activities and four tests were integrated into the course as assignments in both groups. Data were analyzed using a $2 \times 3$ (group and time) mixed ANOVA. The results indicate that BPS did not significantly improve the participants' well-being over time compared with the control group. In fact, the control group performed better than treatment at one month after the intervention. This aligns with recent findings of well-being during COVID-19. Potential implications and areas for future research are discussed.
\end{abstract}

Keywords Positive psychology interventions · Best possible self · Well-being · Undergraduate students

Suzhen Duan

duan63@purdue.edu

Marisa Exter

mexter@purdue.edu

Timothy Newby

newby@purdue.edu

Bingxin Fa

bfa@purdue.edu

1 Learning Design and Technology, Curriculum and Instruction in the College of Education at Purdue University, Steven C. Beering Hall of Liberal Arts and Education 100 N. University Street, West Lafayette, IN 47907-2098, USA

2 Applied Statistics, Purdue University, West Lafayette, IN, USA 


\section{Introduction}

Positive Psychology promises to improve people's lives by helping them strive and flourish to live a self-fulfilled life (Seligman, 2011). Among college students, 94\% indicate that they find happiness more important than wealth (Diener, 2000). However, increasing happiness is not an easy task. Positive Psychology Interventions (PPIs) have proven a promising avenue for increasing happiness and overall well-being (Parks \& Schueller, 2014).

The best possible selves (BPS) intervention is one of the most widely-used, effective PPIs and has been shown to increase well-being, optimism, and positive affect (Carrillo et al., 2019). BPS is a future-oriented intervention that asks participants to describe their best possible future selves, assuming that everything is going well. The high flexibility and salient effects of BPS among undergraduate students make it an ideal tool to be integrated into university classes (Carrillo et al., 2019; Loveday et al., 2016).

However, most BPS studies have been conducted in laboratory settings (Loveday et al., 2016). There is little clear guidance on how these activities can be adapted for the authentic classroom context. This intervention's effectiveness has not been evaluated in a real-world undergraduate classroom setting. While research results in laboratory settings suggest, it may be beneficial to use BPS in the real world, researching the real-world application of this PPI in a classroom setting comes with many challenges. This study pilots the use of BPS in a technology class for undergraduate teacher education students and explores both the immediate and longer-term (one and two months) impact of the intervention on well-being compared to a control group.

This study produced surprising results; the control group outperformed the treatment group, while well-being levels in both groups plummeted at two months after the intervention. As we will discuss in detail in the discussion section, this aligns with documented impact of COVID-19 on well-being as well as the unexpected impact of various types of interventions or strategies during this time period (Satici et al., 2020; Zacher \& Rudolph, 2020). While this was not anticipated when we designed or conducted the study, these findings may be of interest to both educators and researchers.

\section{Literature Review}

\section{Well-Being Defined}

While there have been many definitions of well-being over time (Dodge et al., 2012), at its core, "well-being is more than just happiness. As well as feeling satisfied and happy, well-being means developing as a person, being fulfilled, and making a contribution to the community" (Marks \& Shah, 2004, p. 2). Although different terminology is used across literature on well-being, two main constructs are 
widely used: subjective well-being (SWB) and psychological well-being (PWB) (Keyes et al., 2002). SWB accentuates people's self-reported subjective feelings and experiences of their own life, both affectively and cognitively (Diener, 2000). According to Diener and Suh (1997), "subjective well-being consists of three interrelated components: life satisfaction, pleasant affect, and unpleasant affect. Affect refers to moods and emotions, whereas life satisfaction refers to a cognitive sense of satisfaction with life" (p. 200). In contrast, PWB emphasizes the potential to deal with life's challenges (Keyes et al., 2002) and focuses on traits such as self-acceptance, positive relations with others, environmental mastery, autonomy, purpose in life, and personal growth (Ryff, 1989; Ryff \& Keyes, 1995).

\section{Well-Being of Undergraduate Students}

After material needs are met, people hope to live a more self-fulfilled life (Inglehart, 1990). However, only $20 \%$ of adults achieve this status (Keyes, 2007). Undergraduate students place a high value on well-being; results from a large-scale survey of 7,204 international college students in 42 countries indicate that $94 \%$ of the participants rate happiness as more important than wealth (Diener, 2000). In Positive Psychology on the College Campus, students' success was defined as thriving, which “incorporates not only academic performance and graduation, but it also includes vital engagement and deriving optimal benefits from the college experience" (Wade et al., 2015, p. 8) and that:

By intentionally teaching college students the principles of positive psychology, whether woven into first-year seminar courses or introductory psychology classes, or taught as a singular focus of a course, educators have the potential to equip students with tools they need to thrive in the college years. ( p. 13)

These findings demonstrate the potential value of incorporating positive psychology strategies into mainstream college curricula.

\section{Effects of Positive Psychology Interventions}

Positive psychology aims to improve people's well-being by making ordinary life worth living (Linley \& Joseph, 2004). The core principle of positive psychology is that life's purpose is not merely surviving but also thriving and flourishing (Seligman et al., 2009). Early on, the goal of positive psychology was happiness; in his book, Authentic Happiness, Seligman (2002) focused on three main elements: positive emotion, engagement, and meaning. Later, the goal was expanded from a focus on happiness to a focus on overall well-being by adding two additional elements: relationships and achievement (Seligman, 2011).

Positive Psychology Interventions (PPIs) focus on "well-being, contentment and satisfaction (in the past); hope and optimism (for the future); and flow and happiness (in the present)" (Seligman \& Csikszentmihalyi, 2000, p. 5). PPIs are intentional activities to improve well-being (Sin \& Lyubomirsky, 2009). There are a variety of different PPI activities. For example, three good things asks participants to write 
down three good things that happened to them weekly and reflect on the potential reasons; gratitude visit asks participants to write a gratitude letter to a person they are grateful for and deliver it in person; counting blessings asks participants to list up to five things they are grateful for weekly (Parks \& Schueller, 2014).

PPIs have been shown to improve well-being in a variety of studies. The results of Sin and Lyubomirsky's (2009) meta-analysis, in which 51 PPIs and 4,266 participants were analyzed, showed that PPIs could effectively enhance well-being (mean effect size $r=0.29$ ) immediately after the interventions or over a long-term period. Another meta-analysis evaluated 39 randomized control studies and 6,139 participants, and showed that PPIs effectively enhanced well-being (mean effect size $r=0.34$ for SWB and $r=0.20$ for PWB) immediately after the interventions or over a long-term period (Bolier et al., 2013).

Even though PPIs have been shown to be effective in laboratory settings, more research is needed to study PPIs' effects in real-world settings. Many challenges might threaten the benefits of PPIs, including the macro aspects like culture (Pedrotti, 2014), ethical standards (Vella-Brodrick, 2014), and hedonic adaptation (Bao \& Lyubomirsky, 2014); and micro aspects, such as the level of person-activity fit (Lyubomirsky \& Layous, 2013), the means of assessing outcomes (Duarte, 2014), and inaccurate self-evaluations (Killam \& Kim, 2014).

\section{Effectiveness of the Best Possible Self Intervention}

BPS is one example of an effective PPI (Loveday et al., 2016). BPS was initially developed by Laura King (2001) while studying trauma. In King's study, a total of 81 undergraduate students were asked to write about their best possible future, supposing everything was going well. The writing lasted 20 min per day over four successive days. The results showed that BPS increased well-being and was less upsetting for participants than traditional therapies (e.g., writing about trauma). Participants' well-being increased immediately after the interventions, as well as four weeks later. Furthermore, the intervention led to fewer health center visits three months later. This result was so promising that numerous follow up studies were conducted. Loveday et al. (2016) and Carrillo et al. (2019) confirmed BBP's effectiveness in a systematic review and a meta-analysis, respectively. BPS is an effective intervention to improve well-being (mean effect size $r=0.325$ ), optimism (mean effect size $r=0.334$ ), and positive affect (mean effect size $r=0.511$ ) (Carrillo et al., 2019).

Extensive evidence supports the intervention's effectiveness at increasing wellbeing (Carrillo et al., 2019; Loveday et al., 2016; Lyubomirsky et al., 2011; Manthey et al., 2016), as well as decreasing negative affect (Harrist et al., 2007; Liau et al., 2016). Improvements to well-being were found across a variety of outcomes, including SWB, such as satisfaction with life (Boehm et al., 2011), positive affect (Sheldon \& Lyubomirsky, 2006); and PWB, including flow and happiness (Layous et al., 2013), optimism (Peters et al., 2010), thriving (Heekerens \& Heinitz, 2019), and flourishing (Auyeung \& Mo, 2019). Decreases in negative affect were evidenced by reducing depression, anxiety (Yogo \& Fujihara, 2008), and health center visits 
(King, 2001; Maddalena et al., 2014). However, few studies measured both subjective and psychological well-being. In this study, we hope to measure both subjective and psychological well-being.

\section{The Potential of the Best Possible Self Intervention in the Classroom Setting}

Positive psychology has been embraced by undergraduate students in a number of settings, demonstrating their desire to live a more flourishing life. When Harvard first offered its Positive Psychology course, it quickly became one of the university's most popular electives, with 855 undergraduates enrolled in spring 2006 (Goldberg, 2006). Many universities followed suit by offering similar courses (Ruark, 2009). Experts even called for a thorough application of positive psychology across university campuses to build flourishing communities (Wade et al., 2015). Seligman et al. (2009) claimed that increased well-being is synergistic with better learning and that well-being should and could be taught in classrooms by integrating or embedding PPIs into curricula. This integration can redress a single positive psychology course's coverage limitation and expand PPIs' potential benefits to many university classroom settings.

BPS can be integrated into university curricula. Even though BPS is effective among diverse groups, such as students across educational stages, adults in communities, and patients with mental health symptoms, including suicidal inpatients (Loveday et al., 2016), most studies of BPS focus on undergraduate students. The participants in 19 of the 31 studies in Loveday et al.'s (2016) systematic review and 27 of 29 qualified studies in Carrillo et al.'s (2019) meta-analysis were undergraduate students, making the undergraduate classroom an ideal setting for implementing BPS in the real world.

BPS's flexibility in delivery methods makes it possible to be conducted in realworld classroom settings. Both Loveday et al.'s (2016) systematic review and Carrillo et al.'s (2019) meta-analysis indicated that BPS could be equally effective whether delivered individually or in groups, in person or online, and whether participants used handwriting, speaking, or drawing. BPS's flexibility in length makes it feasible to be implemented in an authentic classroom context. It does not require a significant time investment for each intervention, and long-term effects can be achieved through several repeated interventions. Carrillo et al. (2019) found no statistically significant difference in immediate outcomes between different lengths or intensities of BPS interventions. Lengths ranged from 10 to 75 min during a single intervention, while intensity varied from a single intervention to a 56-day, longterm design. Almost half of the studies (14 out of 29) in Carrillo et al. (2019) used 20-min, single-session BPS interventions, many of which provided strong evidence for BPS's immediate effectiveness in increasing well-being. Furthermore, repeated short BPS interventions could have long-term effects, such as in King's (2001) study, four 20-min BPS interventions over four continuous days showed effects on well-being for four weeks; in Manthey et al.'s (2016) study, eight weeks of continuous BPS writing activities effectively increased SWB throughout the eight weeks, and the effects were maintained when measured again four weeks later. In other 
related studies, the repeated sessions varied from two to eight, and the effects were shown to be maintained when measured from one to six months later (Boehm et al., 2011; Liau et al., 2016; Lyubomirsky et al., 2011; Maddalena et al., 2014).

Although PPIs show salient effects on enhancing well-being in the laboratory setting, and "many people use positive psychological principles in practice, the research on the effectiveness of PPI use in applied settings is seriously lacking" (Parks \& Schueller, 2014, p. xvii). As Parks and Schueller point out:

It may be that what works for one group of happiness seekers would be ineffective or harmful for another group. We need to move beyond question, "are PPIs effective?" to a more nuanced set of questions: "which PPIs are effective, under what circumstances, and for whom?”. (p. xvii)

While short, repeated BPS interventions had both immediate and long-term outcomes in laboratory settings, such research has not been conducted in a realworld classroom. We attempt to fill this gap by designing an experiment to explore whether short, repeated BPS activities completed in the real classroom have longterm effects on undergraduate students' well-being (including SWB and PWB). If the laboratory findings accurately predict what will happen in a real-world setting, an increased level of well-being should persist for at least a semester. As such, our study asks the following research question: Does the researchers' implementation of the BPS intervention influence participants' long-term well-being (including SWB and PWB) in the treatment group compared to the control group over time (three weeks, one month, two months)?

\section{Methods}

\section{Research Design}

The experiment took place in one of the largest classes in the College. A quasiexperimental method was used to assign participants to the treatment and control groups according to the course structure. To measure the long-term effects, three writing activities were arranged over three continuous weeks, and four test-points were set to collect the well-being data. These included pre-test, post-test, one-month follow up, and two-month follow up. Even though the last test point was removed because of the influence of COVID-19, the remaining three test points and two groups still formed a $2 \times 3$ (group and time) repeated measures mixed ANOVA.

\section{Context}

Following approval by the university's Institutional Review Board, this study was conducted during the spring of 2020 at a large, public Midwestern university. The chosen class is one of the largest classes in the College of Education, and it is a required foundational course. The course is offered in both Fall and Spring semester and is typically taken in the freshman year. Since it is an educational technology 
course aiming to prepare the pre-service teacher students to integrate technology in their future teaching, it includes both lecture and lab sessions each week. Lab sections require students to practice a series of technology tools with the help of teaching assistants. In the Spring 2020 semester, this course included two lecture sections and four associated lab groups for each section. The two lectures were offered on Monday mornings and were taught by the same professor, and the labs were offered on Wednesdays and were taught by eight different teaching assistants (TAs). Figure 1 shows the course structure. Since the time spent in the lab is much greater than time spent in the lecture (weekly lab: $110 \mathrm{~min}$, weekly lecture: $50 \mathrm{~min}$ ), all the research activities were conducted during lab time.

\section{Participants}

The participants were undergraduate students enrolled in this course, all of whom are also pre-service teachers majoring in elementary education, social study, special education, etc. In the Spring 2020 semester, a total of 105 students were enrolled in this course. All students were 18 years of age or older, and either freshmen or sophomores; those who completed all of the required activities for this research study were awarded 10 points ( $2.6 \%$ of the 392 points available in the course).

The researchers utilized a quasi-experimental method. Students were assigned to the treatment group (lecture 1: 55 students) or the control group (lecture 2: 50 students) according to lecture sections. There were two reasons for this decision: 1) While students self-registered, the two lecture sections were designed and taught by the same professor, and the four labs for each lecture section were offered on the same day with the same time structure (the students did not know who their TA would be when they enrolled); therefore, the experience was equivalent across

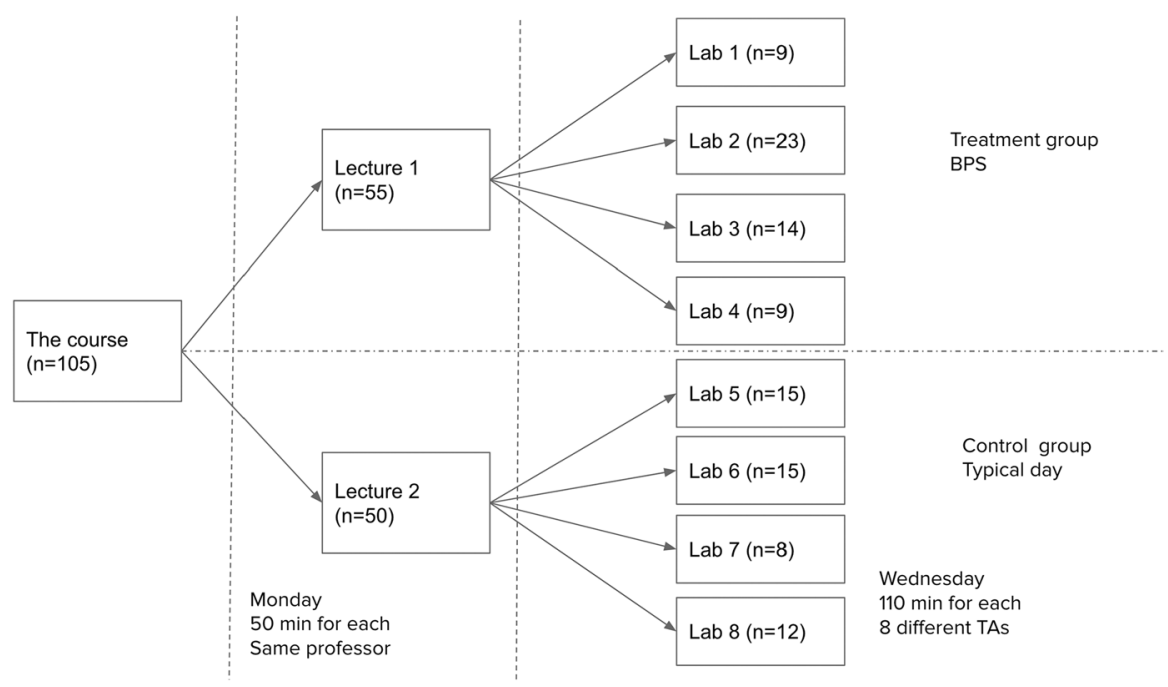

Fig. 1 Course structure 
groups. 2) This design decreased the complexity of distributing the two versions of the study instrument (treatment and control).

The numbers of participants that completed each stage of the study are available at https://osf.io/sg4e6/. Among all the enrolled students $(n=105)$, a total of 12 students did not finish the pre-test (six in each group), seven of them dropped the course, so they could not complete the pre-test, and five of them stayed in the course but did not complete pre-test. Only students who completed all activities (including each of the three writing activities and pre-test, post-test, and one-month follow up) were included in the study (demographic information is available at https://osf.io/sg4e6/).

\section{Procedures}

Data collection was divided into five parts built into different weeks of the 16-week course as assignments. The timeline and the activities are available at https://osf. io/sg4e6/. The participants' well-being was measured four times through the same well-being scales, which were included in the pre-test (Pre, week 2, right before the first writing activity), post-test (Post, week 4, right after the third writing activity), one-month follow up (OneM, week 8, four weeks after the third writing activity), and two-month follow up (TwoM, week 12, eight weeks after the third writing activity) for both the treatment and the control groups; the only difference between the two groups was the content of three writing activities, which were conducted in week 2 , week 3 , and week 4, respectively. The five sections of the intervention were delivered via Qualtrics (all the links are accessible at https://osf.io/sg4e6/.). Course TAs sent the link to the participants during lab time and asked them to complete the assignment during lab time. Pre-test and writing activity 1 , writing activity 2 , writing activity 3 and post-test, and one-month follow up were conducted as planned during lab time. Because of the COVID-19 pandemic, the university closed its campus and transitioned to an online environment after week 9. As such, participants completed two-month follow up from home.

\section{Writing Activity Design}

The writing activities for both the treatment and control groups were adapted from Peters et al. (2010). In Peters et al.'s (2010) study, the writing activity was conducted only once for both groups: BPS for the treatment group, and "A Typical Day" for the control group; the writing activity includes three steps: 1) think about what they will write for one minute; 2) write continuously for $15 \mathrm{~min}$; 3) imagine what they just wrote for $5 \mathrm{~min}$. In this study, because the instructor requested that we keep the activities no longer than 20 min, we adopted only the first two steps. Since research has shown that "the intervention can be equally effective... with or without an explicit imagery component" (Carrillo et al., 2019, p. 19), we opted to eliminate that component from our design. Thus, the estimated time for completing all five parts (including reading the instructions and filling the well-being scales) is $67 \mathrm{~min}$ 
(pre-test \& writing activity1 and writing activity $3 \&$ post-test: 20 min; writing activity 2: $17 \mathrm{~min}$; one-month follow up \& two-month follow up: $5 \mathrm{~min}$ ).

Because we hoped to produce a long-term effect, we designed a repeating series of three writing activities for both groups based on Peters et al.'s (2010) original version. When BPS is used multiple times, the writing prompt is typically changed across times, often by addressing multiple themes. For example, some utilize three themes (personal, professional, relationship) (Meevissen et al., 2011; Peters et al., 2013), four themes (social, health, academic, and career) (Layous et al., 2013), or even eight themes (romantic, hobbies, family, friendship, community, health, career, and free topic) (Manthey et al., 2016). However, the literature does not guide what themes should be used to differentiate BPS prompts when used more than once, and most authors do not justify their selection of themes (Loveday et al., 2016). In this study, we based the themes on the goals of the course and the degree program the activity was embedded in. For the treatment group, we kept Peters et al.'s (2010) original BPS version as the first writing activity, asking the participants to think and write about their best possible self in general. Then, we adapted it to two more writing activities: BPS as a teacher, and BPS of integrating technology tools in teaching, which ask the participants to think and write about their best possible self as a teacher and as a teacher who applies technology tools in their future teaching. We decided to use these two themes because the participants were pre-service teachers, and the course aims to prepare them to integrate technology into their future teaching. We hoped to build a connection among the writing activities, the participants, and the course because relevance is essential to students' motivation (Keller, 1987).

For the control group's writing activities, we adapted Peters et al.'s (2010) A Typical Day to three writing activities: typical weekday (list activities you do in your typical weekday), yesterday (list activities you did yesterday), and typical Saturday (list activities you do in your typical Saturday). Asking participants to write about their typical day is frequently used as a neutral writing activity for the control group in many studies (Carrillo et al., 2019; Loveday et al., 2016). In this study, the difference is that we asked the participants in the control group to write about three typical days: weekday, yesterday, and Saturday.

Each writing activity was delivered through Qualtrics to exclude the potential influence of different TAs' introductions or explanations. Instruction examples of BPS and typical weekday are available at https://osf.io/sg4e6/.

\section{Measurement}

In this study, three scales were used to collect data about both subjective well-being (SWB) and psychological well-being (PWB). All three scales were developed by Diener and his colleagues, who devoted several decades to well-being measures. The Satisfaction with Life Scale (SWLS) (Diener et al., 1985) and Scale of Positive and Negative Experience (SPANEP and SPANEN) (Diener et al., 2010) were used to measure SWB. In this study, SWB was calculated with the formula: $\mathrm{SWB}=\mathrm{SWLS}+\mathrm{SPANEP}-\mathrm{SPANEN}$ (Librán, 2006). The Flourishing Scale (FS) (Diener et al., 2010) was used to measure PWB. 


\section{Satisfaction with Life Scale (SWLS)}

The SWLS is a short 5-item instrument designed to measure global cognitive judgments of satisfaction with one's life (Diener et al., 1985; Pavot \& Diener, 1993). It has been used widely as a measure of the life satisfaction component of subjective well-being. The SWLS is a 7-point Likert-type style response scale ranging from 1 (strongly disagree) to 7 (strongly agree). The possible range of scores is 5-35; higher scores indicate greater satisfaction with life. In Diener et al.'s study (1985), Cronbach's alpha was 0.87 .

\section{The scale of Positive and Negative Experience (SPANE)}

The SPANE measures subjective positive and negative affect (Diener et al., 2010). The scale consists of 12 items, with six each for positive and negative feelings (e.g., good, joyful, bad, angry). It is a 5-point Likert-type scale ranging from 1 (very rarely or never) to 5 (very often or always); the score indicates how often each feeling had been experienced in the last four weeks. In Diener et al.'s (2010) original version, the Cronbach's alpha was 0.87 for positive affect (SPANEP) and 0.81 for the negative affect (SPANEN).

\section{The Flourishing Scale (FS)}

The FS measures psychological well-being and consists of eight items, each using a Likert scale that ranges from 1 (strong disagreement) to 7 (strong agreement) (Diener et al., 2010). The FS contains questions relating to having supportive and rewarding relationships, contributing to others' happiness, being respected by others, having a purposeful and meaningful life, and being engaged and interested in one's activities. In the original version of FS, Cronbach's alpha was 0.87 (Diener et al., 2010).

\section{Data Analysis}

After collecting data, we first visualized the full dataset that contains all four time points. After excluding missing data and outliers, we created a table of descriptive summary of well-being scores as well as visualization of our data. These graphs helped us catch the informative trends and slight changes that may be considered statistically non-significant by the analytical software.

We noted that there was a sharp drop in well-being between the one-month follow-up and two-month follow-up points, which aligned with when campus closed, and students returned home for the rest of the semester due to COVID-19 (which will be further discussed in the discussion section). Therefore, the statistical analysis only compared the other time points.

Since a two-way repeated measures ANOVA requires every subject to go through all experimental conditions, we decided to use two-factor mixed-designed 
ANOVA, which also takes into account the repeated measures issue and the interaction between independent variables. The dependent variables are the SWB and PWB test scores of each student, and the two independent variables are time and group. Each group of students only experienced one kind of intervention, which means that the same subject was only exposed to one condition instead of all conditions. After looking at the analytical results of mixed ANOVA, we conducted the one-way repeated measures ANOVA to examine each group's well-being scores.

Finally, we ran a number of tests to determine whether other factors might have impacted our findings. We also conducted a mixed ANOVA to determine whether demographic differences impacted the dependent variable. Although there was an imbalance between gender and years in school, neither of these variables led to a statistically significant difference in the dependent variable. We also ran independent t-tests to compare words written between the treatment and control groups for each writing activity. There were statistically significant differences between the groups (students in the control group wrote more than the treatment group). We then examined the correlation between writing length and well-being. The only statistically significant correlation we found (at $p<0.05$ ) was between total length of writing across all three activities and the one-month SWLS score $(r(77)=0.243)$ and two-month PWB $(r(77)=0.246)$, and between the length of the third writing activity and the one-month SWLS $(r(77)=0.285)$ and one-month PWB $(r(77)=0.231)$, and two-month PWB $(r(77)=0.283)$. Because these correlations were quite weak and there is no theoretical rationale to explain them, we concluded that writing length had no meaningful relationship with well-being in this study.

\section{Results}

When we visualized the SWB and PWB scores over all time points (pre-test, posttest, one-month follow up, and two-month follow up) in two groups, we noticed unexpectedly sharp drops from the one-month point to the two-month point (Fig. 2(a), (b)). The drastic drop of the score in both SWB and PWB from onemonth follow up to two-month follow up might be a result of the major disruptions in students' lives due to COVID-19. The pandemic could have greatly influenced the effectiveness of the well-being intervention, which we shall discuss after analyzing our data.

As shown in Table 1, the variance difference between pre-test scores for the two groups was not statistically significant for any of the dependent variables, reassuring us that the two groups' starting point is relatively the same. SWB increased slightly between pre- and post-test and between post-test and one-month follow up for each group (Fig. 2(c)). PWB also increased slightly for the control group at these same time points but decreased for the treatment group (Fig. 2(d)).

Before running the model, we first performed Mauchly's test of sphericity to check whether our data met the assumption of equal variances of differences between all combinations of related groups. The violation of sphericity would 
a

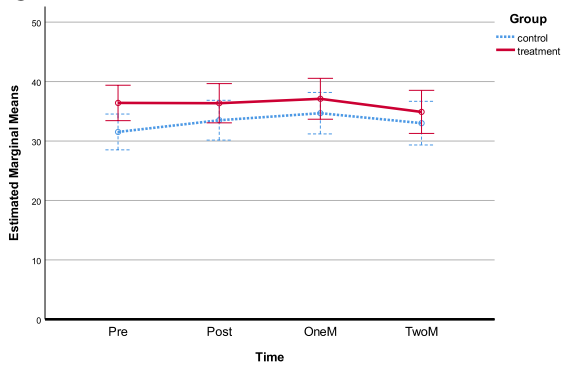

C

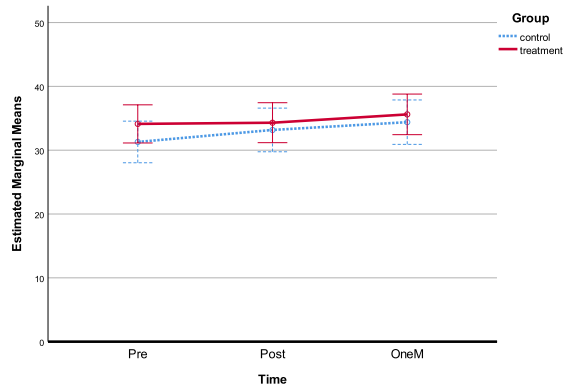

b

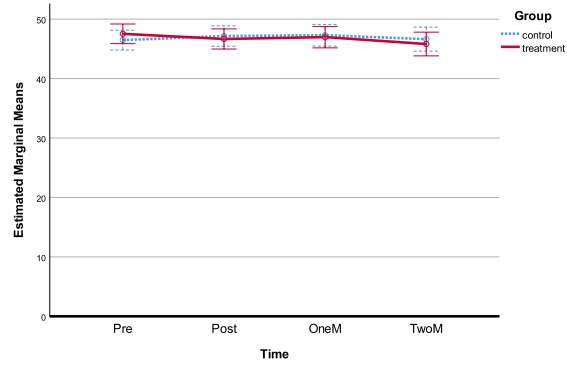

d

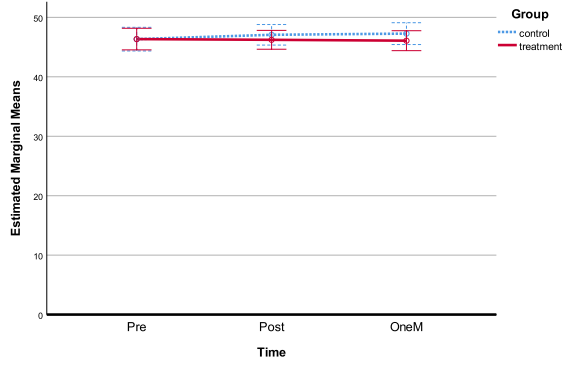

Fig. 2 The SWB and PWB mean scores over time. Note. a and $\mathbf{b}$ include all 77 participants who competed activities across all four test points. $\mathbf{c}$ and $\mathbf{d}$ include all 90 participants who competed activities across pre-test, post-test, and one-month follow up

lead to increased Type I error, making the result more liberal than the reality. Results of Mauchly's test (at $p<0.05$ ) show that PWB did not violate the assumption $(p=0.741)$; however, SWB violated the assumption $(p=0.014)$. Therefore, we used the Greenhouse-Geisser correction $(p=0.914)$, which decreases the variable's degree of freedom to draw a more conservative conclusion.

After checking the assumptions, we ran the analysis. The results are shown in Table 2, which shows the output of mixed ANOVA with repeated measures. The non-significant $p$-value of interaction between time and group indicates that the difference between the treatment group and the control group at each time point is not statistically significant. The group factor's non-significant $p$-value means that considering all time points simultaneously, the treatment group did not behave differently from the control group. The only significant term in this table is the time factor on SWB score $(p=0.002, r=0.257)$. This means that there is at least one group whose score differences were statistically significant across time.

Mixed ANOVA only provides a global data analysis that takes all data into account. It does not tell us which group(s) had significant change over time on the SWB score. In order to obtain a more detailed analysis, we performed a one-way repeated ANOVA for each group separately.

Before running the analysis, we used Mauchly's test to check the equal variance assumption (at $p<0.05$ ). The treatment group did not violate the equal variance assumption $(p=0.165)$. While the control group did violate the assumption 


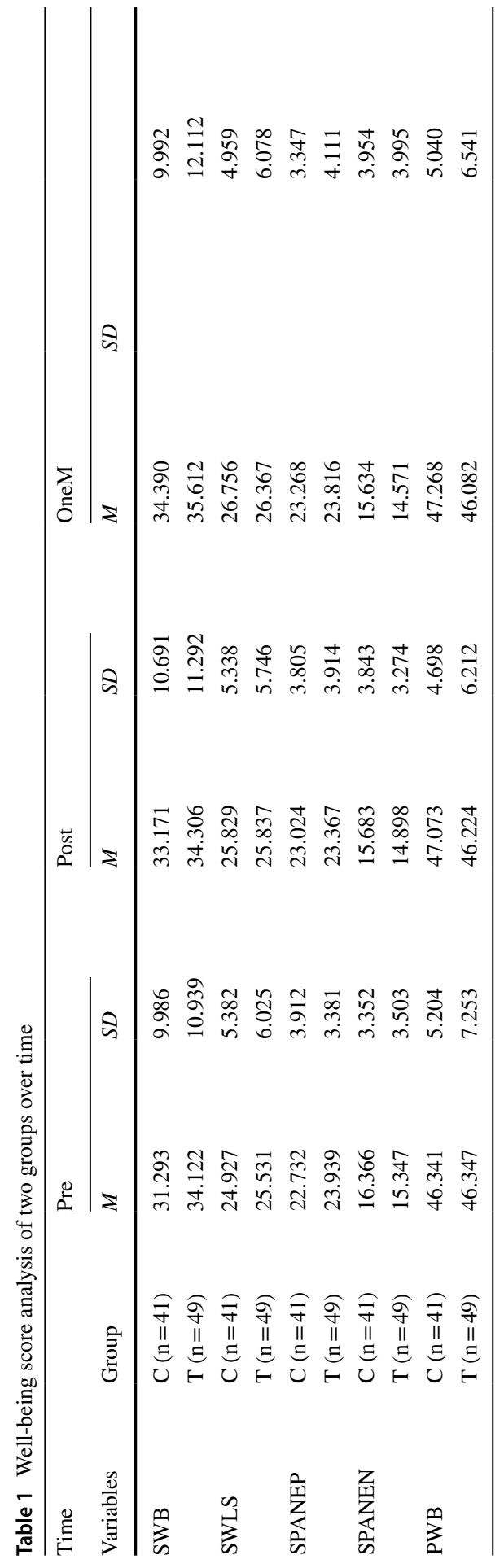


Table 2 Mixed ANOVA repeated measures

\begin{tabular}{lllllll}
\hline & & df & Mean Square & $F$ & p-value & $\begin{array}{l}\text { Partial } \\
\text { Eta } \\
\text { Squared }\end{array}$ \\
\hline SWB & Time & 2 & 117.837 & 6.230 & 0.002 & 0.066 \\
& Group & 1 & 200.205 & 0.626 & 0.431 & 0.007 \\
& Time* Group & 2 & 20.326 & 1.075 & 0.344 & 0.012 \\
PWB & Time & 2 & 3.019 & 0.380 & 0.684 & 0.004 \\
& Group & 1 & 30.658 & 0.337 & 0.563 & 0.004 \\
& Time* Group & 2 & 8.427 & 1.060 & 0.349 & 0.012 \\
\hline
\end{tabular}

$(p=0.033)$, we could use the Greenhouse-Geisser correction to adjust it (Greenhouse-Geisser $p=0.861$ ).

Table 3 is the result of one-way ANOVA repeated measures for both groups. According to the statistics, we concluded that the control group whose SWB score increased significantly from pre-test to one-month follow up) $(p=0.008, r=0.349)$.

\section{Discussion}

The results indicate that the three continuous BPS interventions did not improve the participants' subjective and psychological well-being across all the time points (pretest, post-test, and one-month follow-up) compared with the control group, and wellbeing sharply declined between one-month and two-month follow-up. Contrary to our expectation based on both theory and two decades of laboratory research, the control group showed a more positive trend than the treatment group (Fig. 2). In this discussion, we will first examine our study according to person-activity factors, which likely played some role in our findings. Then, we will discuss the impact of COVID-19 on well-being, comparing and contrasting our findings with those of studies in two other countries. These studies indicate that the effects of interventions with features similar to BPS may not look the same during times of collective trauma as they do in "normal" times.

\section{The Potential Impact of Person-Activity Factors}

Many factors can influence the effectiveness of PPIs. According to Lyubomirsky and Layous et al.'s (2013) positive activity model, person features (e.g., motivation \& effort, efficacy beliefs, demographics), activity features (e.g., length \& frequency, variety),

Table 3 SWB Score Change of both groups over time

\begin{tabular}{llclll}
\hline Group & df & Mean Square & F & Sig & $\begin{array}{l}\text { Partial } \\
\text { Eta } \\
\text { Squared }\end{array}$ \\
\hline Treatment & 2 & 32.333 & 1.635 & 0.200 & 0.033 \\
Control & 1.722 & 115.912 & 5.584 & 0.008 & 0.122 \\
\hline
\end{tabular}


and person-activity fit are three main factors that influence the extent to which PPIs increase participants' well-being.

In terms of person features, this study's sample was a typical group according to the Carrillo et al. (2019) meta-analysis. First, our sample was undergraduate students, which were the majority among all the studies in their meta-analysis (20 out of 29 studies). Second, the mean age of 19 was slightly lower than that of the metaanalysis (23.56). The meta-analysis results indicate that older people experienced better BPS outcomes within the age range of 18 to 35. This might be one reason why this sample experiences less well-being gains through the BPS. Third, females comprised $69 \%$ of our sample, which is slightly lower than the percentage found in the meta-analysis $(74.41 \%)$. Thus, the imbalance of females between the treatment group $(59 \%)$ and the control group (80\%) might be why the control group trended more positively.

Activity features may also play a role in the effectiveness of PPI interventions. In addition to King's (2001) original version, BPS has been revised many times (Austenfeld et al., 2006; Layous et al., 2013; Sheldon \& Lyubomirsky, 2006) to include additions and variations of post-writing activities. This study's BPS was adapted from Peters et al. (2010), except for the last step, which was not included in the present study: five minutes of vivid and detailed imagery. While Carrillo et al.'s (2019) meta-analysis showed equal BPS effectiveness with and without an explicit imagery component among the studies with positive outcomes, the absence of this last step might be one reason our results did not match our expectations.

The writing activities for the control group were adapted from Peters et al. (2010). However, while Peters et al. (2010) only had one round of writing activities, we repeated our activity three times and therefore adapted the Typical Day activity to three different prompts, asking participants to describe a typical weekday, yesterday, and a typical Saturday. The Typical Day is a normal neutral activity for the control group in many studies. In Loveday et al.'s (2016) systematic literature review, eight studies used Typical Day for the control group, and 11 studies used daily related activities either from yesterday, today, or last week for the control group. However, no study asked students to describe a weekend day as we did in our control group activity. We do not know if our adaption changed the "neutral" characteristic of the Typical Day, but we did notice that the participants in the control group wrote significantly more words in all three writing activities than the treatment group. Although there was little evidence of a difference in students' wellbeing based on writing length in this study, we wonder if the inclusion of the weekend day activity prompted more engagement with these activities. Loveday et al.'s (2017) research shows that leisure plays an important role in enhancing well-being. Ryan et al.'s (2010) study shows that weekends and nonworking times are associated with enhancing well-being. Therefore, we recommend that future studies avoid using a weekend day for this type of "neutral" activity in the control group.

In terms of person-activity fit, an earlier study measured the relationship between gender and person-activity fit for three PPIs (expressing gratitude, acts of kindness, and savoring life joys); the results indicated that females showed greater person-activity fit for these three PPIs, and that age correlated positively with the person-activity fit (Thompson et al., 2015). However, no studies have analyzed the 
relationship between person-activity fit and gender or year in school in the BPS area. In this study, we noticed that, while not statistically significant, females and freshmen had higher well-being scores than males and sophomores. This possibly indicates different person-activity fit levels between different genders and ages. More studies are needed to measure the different levels of person-activity fit between different genders and ages for BPS.

\section{Impact of COVID-19}

In addition to the factors discussed above, we believe that our results were likely impacted by the time during which our study occurred. Our study took place during the early stages of the COVID-19 pandemic in the United States. The COVID19 pandemic can be considered an instance of global collective trauma: "collective trauma refers to an entire group's psychological reaction to a traumatic event.... The COVID-19 pandemic is shared not only nationally but also globally, emotionally connecting people around the world through experiences of helplessness, uncertainty, loss, and grief" (Watson et al., 2020, p. 840). In addition to the fear associated with contracting COVID-19, changes to daily life due to social distancing requirements impacted every aspect of students' daily life by the end of the study interval. In particular, as concerns about COVID-19 rose in the United States in March, it became unclear what college would look like for the rest of the spring. By late March, nearly all students had left campus, and all courses were being delivered entirely online.

Zacher and Rudolph (2020) studied the well-being of 972 adults in Germany throughout the winter of 2019 and spring of 2020. Their study showed no statistically significant change in well-being levels between December 2019 and March 2020, largely aligning with our study's results from the pre-test given on January 22 to the one-month follow up on March 4. Well-being sharply decreased in Zacher and Rudolph (2020) between the beginning of March and May 2020, aligning with decreases seen in both our control and treatment groups between the one-month (March 4) and two-month follow up (April 1) points (Fig. 2(a), (b)). This also aligns with the findings of Satici et al.'s (2020) study of 1,772 adults in Turkey, which found a negative correlation between intolerance of uncertainty and well-being during the spring of 2020. Students at our institution were particularly likely to feel increased uncertainty in mid-March, as they awaited the decision regarding whether the campus would be closed and how that would impact their academic and personal lives.

However, we still wondered why our control group had a significant increase in well-being between the pre-test and one-month data and had a less steep decline in PWB between the one-month and two-month points compared to the treatment group (see Fig. 2(b)). Zacher and Rudolph (2020) asked participants to identify which of 14 coping strategies they used to raise their well-being during the spring of 2020, and compared the results from March, April, and May 2020 to data collected in December 2019 (before COVID-19). While their study showed that none of the strategies increased participants' well-being in a statistically significant way during 
the spring months, several surprisingly had the opposite effect; interventions that typically raise well-being actually had a detrimental impact. As Zacher and Rudolph (2020) explain, "individual differences in life satisfaction were... unexpectedly negatively related to planning... the high levels of insecurity associated with the pandemic may have turned future planning into a dissatisfying experience" (pp. 59-60). While Zacher and Rudolph did not explain what was involved in the planning strategy, BPS may have similar effects, as it is future-oriented.

In contrast, the control group in our study was asked to reflect on their current daily life - focused on the present. While this is typically used as a neutral intervention in literature, as it has been shown not to have a significant effect on well-being, it is possible that it could impact people differently during such unusual times. In this study, we also noticed that the participants in the control group wrote significantly more words in their writing activities than students in the treatment group, which might indicate that the participants were more willing or able to write about their daily life than their future.

So, in a time of collective trauma, such as during the COVID-19 pandemic, focusing on daily life may be preferable compared to utilizing an activity that may heighten anxieties related to uncertainty about the future.

\section{Limitations and Implications for Future Research}

Many factors could influence individuals' self-reported well-being scores. Sheldon and Lyubomirsky (2019) evaluated three main factors and the possible degree to which they might affect well-being: "approximately $50 \%$ for genetic factors, $10 \%$ for circumstantial factors, and the remaining $40 \%$ for volitional or intentional activity factors" (p. 1). Even in the laboratory settings, in other words, PPIs are substantially influenced by factors outside the control of researchers (Sheldon \& Lyubomirsky, 2019). In real-world settings, many additional factors might affect PPIs' potential effectiveness, such as BPS in this study.

First, because we were limited by the course structure, participants could not be randomly assigned to the treatment and control groups. Second, seven students dropped the course, and eight students did not complete all the study phases (five did not complete the pre-test, three did not complete the one-month follow up). This makes it impossible to compare these individuals to the larger group and results in a smaller sample size. Third, each activity was designed to last no longer than $20 \mathrm{~min}$ because of the course's tight schedule, including the tests and writing activities. This was one reason the imagery part of the BPS was removed (Peters et al., 2010), which may have influenced the BPS's effects in this study. Fourth, the BPS was only a small portion of the course's learning tasks (only 10 points out of 392 in total). Moreover, students typically take as many as five additional courses simultaneously, such that this activity may not have been particularly prioritized. As discussed above, while it is almost certain that the pandemic affected the final test results, it is also likely that the effects of COVID-19, which began before the first activity on January 22, may have influenced the study's results more broadly. 
This study indicated that what worked in a lab setting did not immediately work in this classroom setting; more research needs to be done to understand and improve BPS's effectiveness in real-world settings. Providing participants with information about BPS's value in the form of reading materials or a short video may help increase their motivation to participate actively. Second, following up with an imagery exercise related to the participants' personal goals might help them imagine their future selves and improve their well-being. Third, it would be valuable to study the immediate effects of each BPS session; this study focused on long-term effects by including a post-test only after three BPS sessions had occurred. Fourth, there is a need to explore further the relationship between person-activity fit and gender or year in school for BPS among undergraduate students. Finally, while the quantitative methods used in this study certainly provided a great deal of information about BPS's effectiveness on this population, it may be equally useful to use qualitative methods such as content analysis, including the quantity and quality of what is written, interviews, and focus groups to better understand individual students' motivations and takeaways.

\section{Conclusion}

Even though this study failed to find significant effects, it contributes to our understanding of applying BPS in real-world settings. This study serves as an example that might reduce some unnecessary stumbling blocks when other instructors try to use it in their classrooms to improve students' well-being. From a broader perspective, as Sheldon and Lyubomirsky (2019) have noted: "Happiness can be successfully pursued, but it is not "easy"' (p. 9). This is partly "because the successful pursuit of happiness typically requires awareness, knowledge, and intentional buy-in by participants" (p. 2). Considering the promise of PPIs, and BPS in particular, in laboratory settings and recommendations made in literature, we believe that continued research in this area could result in evidencesupported best practices for using PPIs in a university classroom setting. Findings of this study and related literature would seem to suggest that BPS may not be an appropriate intervention during times of great crisis (such as the COVID-19 epidemic). However, future studies may continue to explore how to effectively adapt BPS activities to embed within a larger curriculum to improve students' wellbeing. Future studies might also explore whether the "neutral" activity of Typical Day actually is as neutral as it is framed in literature, especially if it is adapted in any way.

Data Availability Not applicable.

Code Availability Not applicable.

Declarations 
Conflicts of Interest/Competing Interests On behalf of all authors, the corresponding author states no conflict of interest.

\section{References}

Austenfeld, J. L., Paolo, A. M., \& Stanton, A. L. (2006). Effects of writing about emotions versus goals on psychological and physical health among third-year medical students. Journal of Personality, 74(1), 267-286.

Auyeung, L., \& Mo, P. K. H. (2019). The efficacy and mechanism of online positive psychological intervention (PPI) on improving well-being among Chinese university students: A pilot study of the best possible self (BPS) intervention. Journal of Happiness Studies, 20, 2525-2550. https:// doi.org/10.1007/s10902-018-0054-4.

Bao, K. J., \& Lyubomirsky, S. (2014). Making happiness last: Using the hedonic adaptation prevention model to extend the success of positive interventions. In A. C. Parks \& S. M. Schueller (Eds.), The Wiley Blackwell handbook of positive psychological interventions. (pp. 373-384). Wiley.

Boehm, J. K., Lyubomirsky, S., \& Sheldon, K. M. (2011). A longitudinal experimental study comparing the effectiveness of happiness-enhancing strategies in Anglo Americans and Asian Americans. Cognition and Emotion, 25(7), 1263-1272. https://doi.org/10.1080/02699931.2010. 541227.

Bolier, L., Haverman, M., Westerhof, G. J., Riper, H., Smit, F., \& Bohlmeijer, E. T. (2013). Positive psychology interventions: A meta-analysis of randomized controlled studies. BMC Public Health, 13(1), 119.

Carrillo, A., Rubio-Aparicio, M., Molinari, G., Enrique, Á., Sánchez-Meca, J., \& Baños, R. M. (2019). Effects of the best possible self intervention: A systematic review and meta-analysis. PLoS One, 14(9). https://doi.org/10.1371/journal.pone.0222386.

Diener, E. (2000). Subjective well-being: The science of happiness and a proposal for a national index. American Psychologist, 55, 34-43. https://doi.org/10.1037/0003-066X.55.1.34.

Diener, E., \& Suh, E. (1997). Measuring quality of life: Economic, social, and subjective indicators. Social Indicators Research, 40, 189-216. https://doi.org/10.1023/A:1006859511756.

Diener, E., Emmons, R. A., Larsen, R. J., \& Griffin, S. (1985). The satisfaction with life scale. Journal of Personality Assessment, 49, 71-75. https://doi.org/10.1207/s15327752jpa4901.

Diener, E., Wirtz, D., Tov, W., Kim-Prieto, C., Choi, D., \& won, Oishi, S Biswas-Diener, R. . (2010). New well-being measures: Short scales to assess flourishing and positive and negative feelings. Social Indicators Research, 97(2), 143-156. https://doi.org/10.1007/s11205-009-9493-y.

Dodge, R., Daly, A., Huyton, J., \& Sanders, L. (2012). The challenge of defining wellbeing. International Journal of Wellbeing, 2(3), 222-235. https://doi.org/10.5502/ijw.v2i3.4.

Duarte, J. L. (2014). Beyond life satisfaction: A scientific approach to well-being gives us much more to measure. In A. C. Parks \& S. M. Schueller (Eds.), The Wiley Blackwell handbook of positive psychological interventions. (pp. 433-449). Wiley.

Goldberg, C. (2006). Harvard's crowded course to happiness. The Boston Globe.

Harrist, S., Carlozzi, B. L., McGovern, A. R., \& Harrist, A. W. (2007). Benefits of expressive writing and expressive talking about life goals. Journal of Research in Personality, 41(4), 923-930.

Heekerens, J. B., \& Heinitz, K. (2019). Looking forward: The effect of the best-possible-self intervention on thriving through relative intrinsic goal pursuits. Journal of Happiness Studies, 20(5), 1379-1395. https://doi.org/10.1007/s10902-018-9999-6.

Inglehart, R. (1990). Culture shift in advanced industrial society Princeton University Press.

Keller, J. M. (1987). Development and use of the ARCS model of instructional design. Journal of Instructional Development, 10(3), 2-10.

Keyes, C. L. M. (2007). Promoting and protecting mental health as flourishing: A complementary strategy for improving national mental health. American Psychologist, 62(2), 95-108. https://doi.org/10. 1037/0003-066X.62.2.95.

Keyes, C. L. M., Shmotkin, D., \& Ryff, C. D. (2002). Optimizing well-being: The empirical encounter of two traditions. Journal of Personality and Social Psychology, 82(6), 1007-1022. https://doi.org/10. 1037/0022-3514.82.6.1007. 
Killam, K. M., \& Kim, Y. H. (2014). Positive psychological interventions and self-perceptions: A cautionary tale. In A. C. Parks \& S. M. Schueller (Eds.), The Wiley Blackwell handbook of positive psychological interventions. (pp. 450-461). Wiley.

King, L. A. (2001). The health benefits of writing about life goals. Personality and Social Psychology Bulletin, 27(7), 798-807. https://doi.org/10.1177/0146167201277003.

Layous, K., Nelson, S. K., \& Lyubomirsky, S. (2013). What is the optimal way to deliver a positive activity intervention? The case of writing about one's best possible selves. Journal of Happiness Studies, 14(2), 635-654. https://doi.org/10.1007/s10902-012-9346-2.

Liau, A. K., Neihart, M. F., Teo, C. T., \& Lo, C. H. M. (2016). Effects of the best possible self activity on subjective well-being and depressive symptoms. Asia-Pacific Education Researcher, 25(3), 473-481. https://doi.org/10.1007/s40299-015-0272-z.

Librán, E. C. (2006). Personality dimensions and subjective well-being. Spanish Journal of Psychology, 9(1), 38-44. https://doi.org/10.1017/S1138741600005953.

Linley, P. A., \& Joseph, S. (Eds.). (2004). Positive psychology in practice Wiley.

Loveday, P. M., Lovell, G. P., \& Jones, C. M. (2016). The best possible selves intervention: A review of the literature to evaluate efficacy and guide future research. Journal of Happiness Studies, 19(2), 607-628. https://doi.org/10.1007/s10902-016-9824-z.

Loveday, P. M., Lovell, G. P., \& Jones, C. M. (2017). The importance of leisure and the psychological mechanisms involved in living a good life: A content analysis of best-possible-selves texts. Journal of Positive Psychology, 13(1), 18-28. https://doi.org/10.1080/17439760.2017.1374441.

Lyubomirsky, S., \& Layous, K. (2013). How do simple positive activities increase well-being? Current Directions in Psychological Science, 22(1), 57-62. https://doi.org/10.1177/0963721412469809.

Lyubomirsky, S., Dickerhoof, R., Boehm, J. K., \& Sheldon, K. M. (2011). Becoming happier takes both a will and a proper way: An experimental longitudinal intervention to boost well-being. Emotion, 11, 391-402. https://doi.org/10.1037/a0022575.

Maddalena, C. J., Saxey-Reese, R., \& Barnes, E. L. (2014). Targeting writing interventions to emotional processing level: A factorial experimental design. Quality and Quantity, 48(6), 2939-2962. https:// doi.org/10.1007/s11135-013-9933-2.

Manthey, L., Vehreschild, V., \& Renner, K. H. (2016). Effectiveness of two cognitive interventions promoting happiness with video-based online instructions. Journal of Happiness Studies, 17(1), 319339. https://doi.org/10.1007/s10902-014-9596-2.

Marks, N., \& Shah, H. (2004). A well-being manifesto for a flourishing society. Journal of Public Mental Health, 3(4), 9-15.

Meevissen, Y. M. C., Peters, M. L., \& Alberts, H. (2011). Become more optimistic by imagining a best possible self: Effects of a two week intervention. Journal of Behavior Therapy and Experimental Psychiatry, 42(3), 371-378. https://doi.org/10.1016/j.jbtep.2011.02.012.

Parks, A. C., \& Schueller, S. M. (Eds.). (2014). The Wiley Blackwell handbook of positive psychological interventions Wiley.

Pavot, W., \& Diener, E. (1993). Review of the satisfaction with life scale. Psychological Assessment, 5, 164-172. https://doi.org/10.1037/1040-3590.5.2.164.

Pedrotti, J. T. (2014). Taking culture into account with positive psychological interventions. In A. C. Parks \& S. M. Schueller (Eds.), The Wiley Blackwell handbook of positive psychological interventions. (pp. 403-415). Wiley.

Peters, M. L., Flink, I. K., Boersma, K., \& Linton, S. J. (2010). Manipulating optimism: Can imagining a best possible self be used to increase positive future expectancies? Journal of Positive Psychology, 5(3), 204-211. https://doi.org/10.1080/17439761003790963.

Peters, M., Meevissen, Y., \& Hanssen, M. (2013). Specificity of the best possible self intervention for increasing optimism: Comparison with a gratitude intervention. Terapia Psicológica, 31(1), 93-100. https://doi.org/10.4067/S0718-48082013000100009.

Ruark, J. K. (2009, August 3). An intellectual movement for the masses. The Chronicle Review. Retrieved from http://chronicle.com/article/An-Intellectual-Movement-for/47500/.

Ryan, R. M., Bernstein, J. H., \& Brown, K. W. (2010). Weekends, work, and well-being: Psychological need satisfactions and day of the week effects on mood, vitality, and physical symptoms. Journal of Social and Clinical Psychology, 29, 95-122.

Ryff, C. D. (1989). Happiness is everything, or is it? Explorations on the meaning of psychological wellbeing. Journal of Personality and Social Psychology, 57(6), 1069-1081. https://doi.org/10.1037/ 0022-3514.57.6.1069. 
Ryff, C. D., \& Keyes, C. L. M. (1995). The structure of psychological well-being revisited. Journal of Personality and Social Psychology, 69(4), 719-727. https://doi.org/10.1002/1520-6696(197801) 14:1\%3c57::AID-JHBS2300140109\%3e3.0.CO;2-7.

Satici, B., Saricali, M., Satici, S. A., \& Griffiths, M. D. (2020). Intolerance of uncertainty and mental wellbeing: Serial mediation by rumination and fear of COVID-19. International Journal of Mental Health and Addiction. https://doi.org/10.1007/s11469-020-00305-0.

Seligman, M. E. P. (2002). Authentic happiness: Using the new positive psychology to realize your potential for lasting fulfillment. Free Press.

Seligman, M. E. P. (2011). Flourish - A new understanding of happiness and well-being - and how to achieve them Nicholas Brealey Publishing.

Seligman, M. E. P., \& Csikszentmihalyi, M. (2000). Positive psychology: An introduction. American Psychologist, 55(1), 5-14.

Seligman, M. E. P., Ernst, R. M., Gillham, J., Reivich, K., \& Linkins, M. (2009). Positive education: Positive psychology and classroom interventions. Oxford Review of Education, 35(3), 293-311. https:// doi.org/10.1080/03054980902934563.

Sheldon, K. M., \& Lyubomirsky, S. (2006). How to increase and sustain positive emotion: The effects of expressing gratitude and visualizing best possible selves. Journal of Positive Psychology, 1(2), 73-82. https://doi.org/10.1080/17439760500510676.

Sheldon, K. M., \& Lyubomirsky, S. (2019). Revisiting the sustainable happiness model and pie chart: Can happiness be successfully pursued? Journal of Positive Psychology. https://doi.org/10.1080/ 17439760.2019.1689421.

Sin, N. L., \& Lyubomirsky, S. (2009). Enhancing well-being and alleviating depressive symptoms with positive psychology interventions: A practice-friendly meta-analysis. Journal of Clinical Psychology, 65(5), 467-487. https://doi.org/10.1002/jclp.

Thompson, R. B., Peura, C., \& Gayton, W. F. (2015). Gender differences in the person-activity fit for positive psychology interventions. Journal of Positive Psychology, 10(2), 179-183. https://doi.org/ 10.1080/17439760.2014.927908.

Vella-Brodrick, D. A. (2014). Dovetailing ethical practice and positive psychology to promote integrity, industriousness, innovation, and impact. In A. C. Parks \& S. M. Schueller (Eds.), The Wiley Blackwell handbook of positive psychological interventions. (pp. 416-432). Wiley.

Wade, J. C., Marks, L. I., \& Hetzel, R. D. (Eds.). (2015). Positive psychology on the college campus. Oxford University Press.

Watson, M. F., Bacigalupe, G., Daneshpour, M., Han, W. J., \& Parra-Cardona, R. (2020). COVID-19 interconnectedness: Health inequity, the climate crisis, and collective trauma. Family Process, 59(3), 832-846. https://doi.org/10.1111/famp.12572.

Yogo, M., \& Fujihara, S. (2008). Working memory capacity can be improved by expressive writing: A randomized experiment in a Japanese sample. British Journal of Health Psychology, 13(1), 77-80. https://doi.org/10.1348/135910707X252440.

Zacher, H., \& Rudolph, C. W. (2020). Individual differences and changes in subjective wellbeing during the early stages of the COVID-19 pandemic. American Psychologist, 76(1), 50-62. https://doi.org/ 10.1037/amp0000702.

Publisher's Note Springer Nature remains neutral with regard to jurisdictional claims in published maps and institutional affiliations. 